\title{
PENGARUH MOTIVASI KERJA DAN DISIPLIN KERJA TERHADAP KINERJA PEGAWAI PADA PUSKESMAS RANTAU IKIL KABUPATEN BUNGO
}

\section{Supriyati, Boy Supandi Pangaribuan}

Program Studi Manajemen Fakultas Ekonomi

Universitas Muara Bungo

\begin{abstract}
ABSTRAK
Tujuan dilakukan penelitian ini adalah untuk mengetahui pengaruh Motivasi Kerja dan Disiplin Kerja Terhadap Kinerja Pegawai Pada Puskesmas Rantau Ikil Kecamatan Jujuhan Kabupaten Bungo.

Metode penelitian ini pendekatan kuantitatif dengan metode sampling jenuh yang berjumlah 87 orang yang merupakan pegawai Pada Puskesmas Rantau Ikil Kecamatan Jujuhan, Hasil analisis regresi berganda yaitu $Y=1.260+0.249\left(X_{1}\right)+0.819\left(X_{2}\right)+$ e. Hasil uji parsial dan secara simultan berpengaruh positif dan signifikan terhadap kinerja (Y) kinerja pegawai Puskesmas Rantau Ikil Kabupaten Bungo dan didapat nilai $R$ Square 0.480 atau $48 \%$. sedangkan sisanya sebesar $52 \%$ dipengaruhi oleh faktor lainya yang tidak diteliti dalam penelitian ini.
\end{abstract}

Kata Kunci :Motivasi Kerja, Disiplin kerja, Kinerja pegawai.

\section{PENDAHULUAN}

Puskesmas Rantau Ikil adalah sebuah instansi yang melayani masyarakat dan puskesmas ini terletak dikecamatan jujuhan kabupaten bungo dimana lingkungannya sangat strategis terletak di dekat jalan lintas. Peningkatan kualitas pelayanan yang dilakukan yaitu melalui peningkatan kinerja pegawai dalam melaksanakan tugasnya dan kewajibannya. Puskesmas Rantau Ikil memiliki 87 pegawai, diantaranya PNS 36 orang dan TKD 51 orang.

Tabel 1 Hasil Pencapaian Evaluasi Kinerja Pegawai Puskesmas Rantau Ikil Tahun 2019

\begin{tabular}{|c|l|c|l|l|}
\hline NO & $\begin{array}{l}\text { KOMPONEN KEGIATAN } \\
\text { UPAYA KESEHATAN } \\
\text { WAJIB }\end{array}$ & $\begin{array}{c}\text { HASIL } \\
\text { CAKUPAN } \\
(\%)\end{array}$ & $\begin{array}{l}\text { TINGKAT } \\
\text { KINERJA }\end{array}$ & KETERANGAN \\
\hline 1 & PROMOSI KESEHATAN & $87,27 \%$ & Baik & Baik $\geq 85 \%$ \\
\hline 2 & $\begin{array}{l}\text { KESEHATAN } \\
\text { LINGKUNGAN }\end{array}$ & $83,50 \%$ & Cukup & $\begin{array}{l}\text { Cukup } \geq 55- \\
84 \%\end{array}$ \\
\hline 3 & $\begin{array}{l}\text { KESEHATAN IBU DAN } \\
\text { ANAK TERMASUK KB }\end{array}$ & $94,41 \%$ & Baik & Kurang <55\% \\
\hline 4 & $\begin{array}{l}\text { UPAYA PERBAIKAN GIZI } \\
\text { MASYARAKAT }\end{array}$ & $86,17 \%$ & Baik & \\
\hline 5 & $\begin{array}{l}\text { UPAYA PENCEGAHAN } \\
\text { DAN PEMBERANTASAN } \\
\text { PENYAKIT MENULAR }\end{array}$ & $86,07 \%$ & Baik & \\
\hline 6 & UPAYA PENGOBATAN & $81,32 \%$ & Cukup & \\
\hline 7 & UPAYA KESEHATAN & $94,14 \%$ & Baik & \\
\hline
\end{tabular}




\begin{tabular}{|l|l|l|l|l|}
\hline PENGEMBANGAN & & & \\
\hline Rata-rata Kinerja & $87,55 \%$ & Baik & \\
& & & \\
\hline
\end{tabular}

Sumber: Data Evaluasi Kinerja Pegawai Puskesmas Rantau Ikil Tahun 2019

Kinerja pegawai Puskesmas Rantau Ikil belum memuaskan dikarenakan masih ada target yang belum terlaksanakan, Oleh karena itu keberhasilan suatu perusahaan dilihat dari kemampuan perusahaan dalam meningktakan kinerja karyawannya dengan melihat kemauan atau dorongan untuk bekerja sebaik mungkin agar tercapai tujuan perusahaan yang maksimal yang telah ditetapkan perusahaan sehingga dengan adanya motivasi dan disiplin kerja dari karyawan dapat mengarahkan kemampuan, keahlian, keterampilan dan mematuhi peraturan dalam melaksanakan tugas kinerja karyawan akan lebih baik (Nur Hidayat, 2014). Berdasarkan uraian yang telah dikemukakan di atas maka yang menjadi rumusan masalah dalam penelitian ini adalah: Bagaimanakah pengaruh Motivasi kerja dan disiplin Kerja terhadap Kinerja Pegawai di Puskesmas Rantau Ikil Kecamatan Jujuhan Kabupaten Bungo secara simultan dan parsial.

Adapun yang menjadi tujuan penelitian yang ingin dicapai yaitu: Untuk mengetahui Pengaruh Motivasi Kerja Dan DisiplinKerja Terhadap Kinerja Pegawai Pada Puskesmas Rantau Ikil Kecamatan Jujuhan Kabupaten Bungo.

\section{KAJIAN PUSTAKA}

\section{Motivasi Kerja}

Motivasi Kerja adalah Kekuatan, baik dari dalam maupun dari luar yang mendorong seseorang untuk mencapai tujuan tertentu yang telah ditetapkan sebelumnya. (Hamzah B. Uno,2009) Indikator yang digunakan adalah :
1.Tanggung Jawab dalam melakukan kerja

2. Prestasi yang dicapainya

3. Pengembangan diri

4. Kemandirian dalam bertindak

Menurut Hamzah B. Uno (2009)

Disiplin Kerja

disiplin kerja adalah perilaku seseorang yang sesuai dengan peraturan, prosedur kerja yang ada atau disiplin adalah sikap, tingkah laku dan perbuatan yang sesuai dengan peraturan dari organisasi baik tertulis maupun yang tidak tertulis. Menurut Sutrisno (2009).

Indikator yang digunakan :

1. Tata terhadap aturan waktu

2. Taat terhadap peraturan perusahaan

3. Taat terhadap aturan perilaku akan pekerjaan

4. Taat terhadap peraturan lainnya di perusahaan.

Menurut Sutrisno (2009)

Kinerja

Pengertian kinerja (prestasi kerja) adalah hasil kerja secara kualitas dan kuantitas yang dicapai oleh seorang pegawai dalam melaksanakan tugasnya sesuai dengan tanggung jawab yang diberikan kepadanya. Menurut Mangkunegara (2015).

Indikator yang digunakan

1. Kualitas Kerja

2. Kuantitas Kerja

3. Pelaksanaan Tugas

4. tanggung Jawab

Menurut Mangkunegara (2011) 


\section{Gambar 1 Kerangka Konseptual}

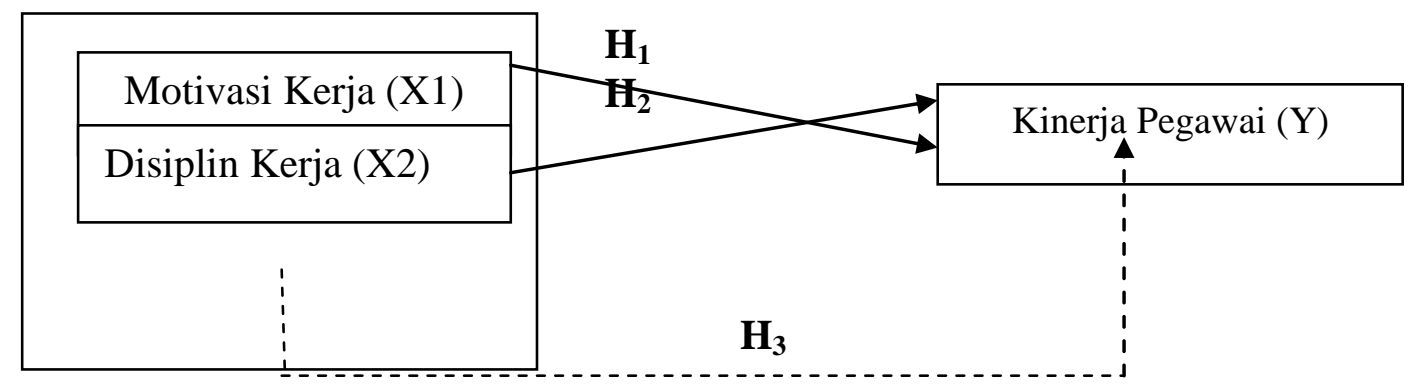

Keterangan :

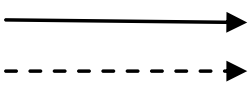

Parsial

simultan

\section{Hipotesis}

Hipotesis yang akan diuji dalam penelitian ini adalah:

1. $\mathrm{H}_{1}$ : Terdapat Pengaruh Signifikan Dari

Motivasi Kerja (X1)

Terhadap Kinerja

Pegawai (Y) Secara

Parsial.

2. $\mathrm{H}_{2}$ : Terdapat Pengaruh Signifikan Disiplin

kerja (X2) Terhadap

kinerja Pegawai (Y)

Secara Parsial.

3. $\mathrm{H}_{3}$ : Terdapat Pengaruh

Signifikan Motivasi

Kerja (X1) Dan

Disiplin Kerja (X2)

Terhadap Kinerja

Pegawai (Y) Secara

Simultan.

\section{Metode Penelitian}

Objek dalam penelitian ini adalah Kinerja Pegawai pada Puskesmas
Rantau ikil Kecamatan Jujuhan Kabupaten Bungo.

Populasi dalam penelitian ini adalah seluruh pegawai Puskesmas yang berjumlah 87 orang

Teknik pengambilan sampel yang digunakan dalam penelitian ini adalah Metode Sampling Jenuh, yaitu seluruh populasi dijadikan sampel (Sugiyono, 2015) maka yang dijadikan sampel yakni 87 orang.

\section{Metode Analisis}

Data

Menurut Sugiyono (2012), persamaan analisis regresi linear berganda dapat dirumuskan sebagai berikut: $\mathbf{Y}=\mathbf{a}+$ $\mathbf{b}_{\mathbf{i}} \mathbf{X}_{1+} \mathbf{b}_{2} \mathbf{X}_{2}+\mathbf{e}$

Ket:

$\mathrm{Y}=$ Kinerja pegawai $\quad \mathrm{a}=$ Konstanta

$\mathrm{X} 1$ = Motivasi Kerja

X2 = Disiplin Kerja

bi $=$ Koefisien Regresi

$\mathrm{e}=$ Standar error

Pengujian Hipotesis

Uji t (Uji Secara Parsial)

Uji F (Uji Secara Simulatan 
Hasil dan Pembahasan

\section{Uji Validitas}

Tabel 2Hasil Uji Validitas

\begin{tabular}{|c|c|c|c|c|}
\hline Variabel & Pernyataan & $\mathbf{r}_{\text {hitung }}$ & $\mathbf{r}_{\text {tabel }}$ & Keterangan \\
\hline \multirow{4}{*}{$\begin{array}{c}\text { Motivasi } \\
\text { Kerja }\end{array}$} & Item 1 & 0,732 & 0,2108 & Valid \\
\cline { 2 - 5 } & Item 2 & 0,735 & 0,2108 & Valid \\
\cline { 2 - 5 } & Item 3 & 0,492 & 0,2108 & Valid \\
\cline { 2 - 5 } & Item 4 & 0,341 & 0,2108 & Valid \\
\cline { 2 - 5 } & Item 5 & 0,409 & 0,2108 & Valid \\
\cline { 2 - 5 } & Item 6 & 0,530 & 0,2108 & Valid \\
\cline { 2 - 5 } & Item 7 & 0,441 & 0,2108 & Valid \\
\cline { 2 - 5 } & Item 8 & 0,458 & 0,2108 & Valid \\
\hline \multirow{4}{*}{ Kisiplin } & Item 1 & 0,700 & 0,2108 & Valid \\
\cline { 2 - 5 } & Item 2 & 0,558 & 0,2108 & Valid \\
\cline { 2 - 5 } & Item 3 & 0,575 & 0,2108 & Valid \\
\cline { 2 - 5 } & Item 4 & 0,752 & 0,2108 & Valid \\
\cline { 2 - 5 } & Item 5 & 0,603 & 0,2108 & Valid \\
\cline { 2 - 5 } & Item 6 & 0,363 & 0,2108 & Valid \\
\cline { 2 - 5 } & Item 7 & 0,830 & 0,2108 & Valid \\
\cline { 2 - 5 } & Item 8 & 0,230 & 0,2108 & Valid \\
\cline { 2 - 5 } & Item 1 & 0,664 & 0,2108 & Valid \\
\cline { 2 - 5 } & Item 2 & 0,678 & 0,2108 & Valid \\
\cline { 2 - 5 } & Item 3 & 0,763 & 0,2108 & Valid \\
\cline { 2 - 5 } & Item 4 & 0,525 & 0,2108 & Valid \\
\cline { 2 - 5 } & Item 5 & 0,664 & 0,2108 & Valid \\
\cline { 2 - 5 } & Item 6 & 0,751 & 0,2108 & Valid \\
\cline { 2 - 5 } & Item 7 & 0,405 & 0,2108 & Valid \\
\cline { 2 - 5 } & Item 8 & 0,536 & 0,2108 & Valid \\
\hline Pegawai & & & \\
\hline
\end{tabular}

Sumber : data primer, diolah 2020

Berdasarkan output diatas dapat dilihat bahwa semua item pernyataan pada ketiga variabel yang diuji berkolerasi signifikan dengan skor total. Ini dapat dilihat dari jika $r_{\text {hitung }}$ lebih besar dari $r_{\text {tabel }}$. $r_{\text {tabel, }}$ nilai sebesar 0,2108. Sehingga dapat disimpulkan bahwa semua butir instrument valid dan dapat digunakan untuk analisis data selanjutnya.

\section{Uji Reliabilitas}

Item pernyataan dalam kuesioner dinyatakan reliable jika memiliki nilai koefisien Cronbach's Alpha lebih besar dari 0,60 (Sugiyono, 2015).

Tabel 3Hasil Uji Reliabilitas

\begin{tabular}{|c|c|c|c|}
\hline Variabel & $\begin{array}{c}\text { Nilai } \\
\text { Cronbach's } \text { Alpha }\end{array}$ & $\begin{array}{c}\text { Batas } \\
\text { Reliabilitas }\end{array}$ & Keterangan \\
\hline Motivasi Kerja & 0,616 & 0,60 & Reliable \\
\hline Disiplin Kerja & 0,725 & 0,60 & Reliabel \\
\hline Kinerja Pegawai & 0,775 & 0,60 & Reliabel \\
\hline
\end{tabular}

Sumber : data primer, diolah 2019 
Berdasarkan tabel diatas, hasil pengujian data menunjukkan setiap butirbutir pernyataan pada masing-masing variabel penelitian mempunyai Cronbach's Alpha > 0,60 sehingga seluruh butir-butir pernyataan pada masing-masing variabel penelitian dinyatakan reliable dan dapat disebarkan kepada responden untuk dijadikan instrument penelitian.

\section{Hasil Uji Asumsi Klasik \\ Uji Normalitas}

\section{Gambar 2}

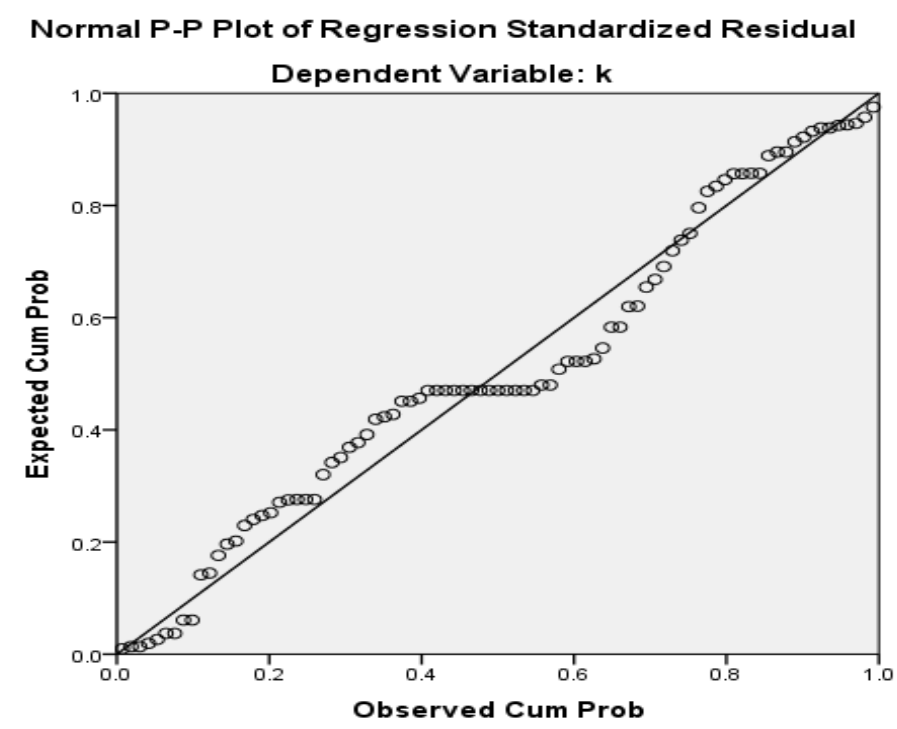

Tabel 4

\section{Hasil Uji Multikolinieritas}

\begin{tabular}{|c|c|c|c|c|c|c|c|}
\hline \multirow[b]{2}{*}{ Model } & \multicolumn{2}{|c|}{$\begin{array}{l}\text { Unstandardized } \\
\text { Coefficients }\end{array}$} & \multirow{2}{*}{$\begin{array}{c}\begin{array}{c}\text { Standardize } \\
\mathrm{d}\end{array} \\
\text { Coefficients } \\
\text { Beta }\end{array}$} & \multirow[b]{2}{*}{$\mathrm{T}$} & \multirow[b]{2}{*}{ Sig. } & \multicolumn{2}{|c|}{$\begin{array}{l}\text { Collinearity } \\
\text { Statistics }\end{array}$} \\
\hline & B & Std. Error & & & & $\begin{array}{c}\text { Toleran } \\
\text { ce }\end{array}$ & VIF \\
\hline (Constant) & $\begin{array}{r}14.99 \\
9\end{array}$ & 1.444 & & $\begin{array}{r}10.38 \\
5\end{array}$ & .000 & & \\
\hline $\mathrm{x} 1$ & .629 & .070 & .760 & 8.997 & .000 & .761 & 1.314 \\
\hline $\mathrm{x} 2$ & .093 & .033 & .242 & 2.867 & .007 & .761 & 1.314 \\
\hline
\end{tabular}

a. Dependent Variable: $y$

Berdasarkan tabel diatas dapat dilihat bahwa nilai Tolerance pada masing-masing variabel bebas besarnya diatas 0,1 dan VIF dibawah 10. Ini menunjukkan bahwa tidak ada Multikolinieritas diantara variabel bebas.

\section{Hasil Uji Heteroskedastisitas}

\section{Gambar 3}




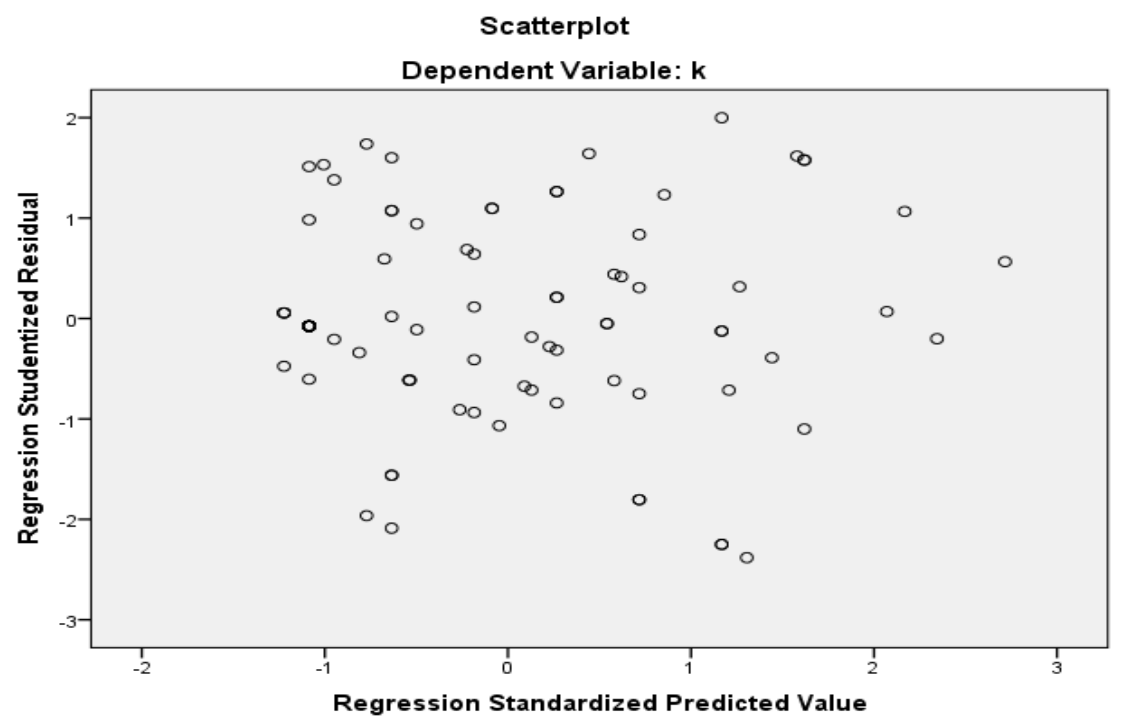

Dari grafik scatterplot di atas dapat dilihat bahwa titik-titik menyebar diatas dan dibawah angka 0 pada sumbu y tanpa membentuk pola tertentu. Maka dapat disimpulkan tidak terjadi Heteroskedastisitas pada model regresi.

\section{Analisis Regresi Berganda}

Hasil analisis regresi linier berganda dari penelitian ini pada tabel berikut ini :

Tabel 5

Cooficients $^{\mathrm{a}}$

\begin{tabular}{|c|c|c|c|c|c|}
\hline \multirow[b]{2}{*}{ Model } & \multicolumn{2}{|c|}{$\begin{array}{c}\text { Unstandardized } \\
\text { Coefficients }\end{array}$} & $\begin{array}{c}\text { Standardized } \\
\text { Coefficients }\end{array}$ & $\mathrm{T}$ & Sig. \\
\hline & $\mathrm{B}$ & Std. Error & Beta & & \\
\hline $1 \quad$ (Constant) & 1.260 & 4.559 & & .276 & .783 \\
\hline $\mathrm{x} 1$ & .249 & .106 & .185 & 2.354 & .021 \\
\hline $\mathrm{x} 2$ & .819 & .096 & .672 & 8.533 & .000 \\
\hline
\end{tabular}

b. Dependent Variable: y

Sumber : Output SPSS (olah data)

Berdasarkan tabel 4.22 di atas dapat diperoleh persamaan regresi sebagai berikut :

$$
Y=1.260+0.249\left(X_{1}\right)+0.819
$$
$\left(\mathbf{X}_{2}\right)+\mathbf{e}$

Penjelasan dari regresi linier berganda secara parsial adalah sebagai berikut :

a. Konstanta $=1.260$

Jika variabel motivasi kerja dan disiplin kerja dianggap sama dengan nol, maka variabel kinerja adalah 1.260. b. Koefisien Regresi Motivasi Kerja $=0.249$

Jika variabel motivasi kerja mengalami kenaikan 1 satuan, sementara variabel disiplin kerja diasumsi tetap, maka kinerja Pegawai Puskesmas Rantau Ikil Kabupaten Bungo akan meningkat sebesar 0.249.

c. Koefisien Regresi Disiplin Kerja $=0.819$

Jika variabel Motivasi kerja mengalami kenaikan 1 satuan, 
sementara variabel Motivasi

kerja diasumsi tetap, maka kinerja akan meningkat sebesar 0.819 .

\section{Hasil Pengujian Hipotesis Uji-t}

\section{Tabel 6}

Hasil Uji - $\mathrm{t}$

Cooficients $^{\mathrm{a}}$

\begin{tabular}{|c|c|c|c|c|c|}
\hline \multirow[b]{2}{*}{ Model } & \multicolumn{2}{|c|}{$\begin{array}{c}\text { Unstandardized } \\
\text { Coefficients }\end{array}$} & $\begin{array}{c}\text { Standardized } \\
\text { Coefficients }\end{array}$ & $\mathrm{T}$ & Sig. \\
\hline & $\mathrm{B}$ & Std. Error & Beta & & \\
\hline $1 \quad$ (Constant) & 1.260 & 4.559 & & .276 & .783 \\
\hline $\mathrm{x} 1$ & .249 & .106 & .185 & 2.354 & .021 \\
\hline $\mathrm{x} 2$ & .819 & .096 & .672 & 8.533 & .000 \\
\hline
\end{tabular}

b. Dependent Variable: y

Sumber : Output SPSS (olah data)

1. Uji parsial untuk variabel motivasi kerja $\left(\mathrm{X}_{1}\right)$ dengan kinerja pegawai $(\mathrm{Y})$ nilai $t_{\text {hitung }}(2,354)>t_{\text {tabel }}(1,98861)$, sehingga $\mathrm{H}_{0}$ ditolak dan $\mathrm{H}_{\mathrm{a}}$ diterima. Artinya, secara parsial variabel motivasi kerja berpengaruh terhadap kinerja pegawai Puskesmas Rantau Ikil Kabupaten Bungo

Hasil Uji F (simultan)
2. Uji parsial untuk variabel disiplin kerja $\left(\mathrm{X}_{2}\right)$ dengan kinerja pegawai

Hasil uji parsial, variabel disiplin kerja $\left(\mathrm{X}_{2}\right)$ berpengaruh signifikan terhadap kinerja pegawai (Y) pada Puskesmas Rantau Ikil Kabupaten Bungo. Hal ini terlihat dari nilai thitung $(8,533)>\mathrm{t}_{\text {tabel }}$ (1,98861), sehingga $\mathrm{H}_{0}$ ditolak dan $\mathrm{H}_{\mathrm{a}}$ diterima.

Tabel 7

Hasil Uji F (simultan)

\begin{tabular}{|l|l|r|r|r|r|c|}
\hline \multicolumn{7}{|c|}{ ANOVA $^{\text {a }}$} \\
\hline \multirow{2}{|l|}{\begin{tabular}{l} 
Model \\
\hline \multirow{2}{*}{1}
\end{tabular}} & $\begin{array}{c}\text { Sum of } \\
\text { Squares }\end{array}$ & Df & Mean Square & F & Sig. \\
\cline { 2 - 7 } & Regression & 283.406 & 2 & 141.703 & 38.716 & $.000^{\mathrm{b}}$ \\
\cline { 2 - 7 } & Residual & 307.445 & 84 & 3.660 & & \\
\cline { 2 - 7 } & Total & 590.851 & 86 & & & \\
\hline
\end{tabular}

Sumber : Output SPSS (olah data)

Berdasarkan output Anova di atas dapat dilihat bahwa nilai $F_{\text {hitung }}$ adalah 38,716 lebih besar dari $F_{\text {tabel }}$ sebesar 3,11. Sehingga $\mathrm{H}_{0}$ ditolak dan $\mathrm{H}_{\mathrm{a}}$ diterima. Maka dapat disimpulkan bahwa varibel motivasi kerja (X1) dan disiplin kerja (X2) secara simultan berpengaruh positif dan signifikan terhadap kinerja (Y) kinerja pegawai Puskesmas Rantau Ikil Kabupaten Bungo.

\section{Koefisien Determinasi $\left(\mathbf{R}^{2}\right)$}


Tabel 8

Hasil Uji Koefisiensi Determinasi $\left(\mathbf{R}^{2}\right)$
\begin{tabular}{|l|r|r|r|r|} 
Model Summary \\
\hline
\end{tabular}
Model

a. Predictors: (Constant), x2, x1

Sumber : Output SPSS (olah data)

$R$ Square sebesar 0,467 atau $46,7 \%$, nilai tersebut menunjukkan besarnya kontribusi yang dapat dijelaskan oleh variabel bebas motivasi dan disiplin kerja secara bersama-sama terhadap variabel terikat (Y) sedangkan sisanya sebesar 53,3\% dipengaruhi oleh variabel lain diluar penelitian.

\section{Pembahasan.}

Uji parsial untuk variabel motivasi kerja $\left(\mathrm{X}_{1}\right)$ dengan kinerja pegawai (Y) dengan nilai $t_{\text {hitung }}$ $(2,354)>t_{\text {tabel }}(1,98861)$, sehingga $\mathrm{H}_{0}$ ditolak dan $\mathrm{H}_{\mathrm{a}}$ diterima. Artinya, secara parsial variabel motivasi kerja berpengaruh terhadap kinerja pegawai Puskesmas Rantau Ikil Kabupaten Bungo.Hasil uji parsial, variabel disiplin kerja $\left(\mathrm{X}_{2}\right)$ berpengaruh signifikan terhadap kinerja pegawai (Y) pada Puskesmas Rantau Ikil Kabupaten Bungo. Hal ini terlihat dari nilai thitung $(8,533)$ $>t_{\text {tabel }}(1,98861)$, sehingga $\mathrm{H}_{0}$ ditolak dan $\mathrm{H}_{\mathrm{a}}$ diterima. Secara Simultan bahwa nilai $F_{\text {hitung }}$ adalah 38,716 lebih besar dari $F_{\text {tabel }}$ sebesar 3,11. Sehingga $\mathrm{H}_{0}$ ditolak dan $\mathrm{H}_{\mathrm{a}}$ diterima. Maka dapat disimpulkan bahwa varibel motivasi kerja (X1) dan disiplin kerja (X2) secara simultan berpengaruh positif dan signifikan terhadap kinerja $(\mathrm{Y})$ kinerja pegawai Puskesmas Rantau Ikil Kabupaten Bungo. $R$ Square sebesar 0,467 atau $46,7 \%$, nilai tersebut menunjukkan besarnya kontribusi yang dapat dijelaskan oleh variabel bebas motivasi dan disiplin kerja secara bersama-sama terhadap variabel terikat (Y) sedangkan sisanya sebesar 53,3\% dipengaruhi oleh variabel lain diluar penelitian

Hasil penelitian ini sejalan dengan penelitian yang dilakukan oleh Yohannes Delvin Ardianto (2017) yang meneliti tentang Analisis Pengaruh Motivasi Kerja Dan Disiplin Kerja Terhadap Kinerja Karyawan Di Devisi Fabrikasi Direktorat Produksi PT. Industri Kereta Api (PT.INKA) Madium.

\section{PENUTUP}

\section{Kesimpulan}

kesimpulan dalam penelitian ini sebagai berikut :

1. Uji parsial variabel motivasi kerja $\left(\mathrm{X}_{1}\right)$ didapatkan nilai $\mathrm{t}_{\text {hitung }}(2,354)>$ $t_{\text {tabel }}(1,98861)$, dan variabel disiplin kerja $\left(\mathrm{X}_{2}\right)$ didapatkan nilai $\mathrm{t}_{\text {hitung }}(8,533)>\mathrm{t}_{\text {tabel }}$ (1,98861), sehingga $\mathrm{H}_{0}$ ditolak dan $\mathrm{H}_{\mathrm{a}}$ diterima. Artinya, secara parsial variabel motivasi kerja dan disiplin kerja berpengaruh terhadap kinerja pegawai. Hasil uji parsial, variabel disiplin kerja $\left(\mathrm{X}_{2}\right)$ berpengaruh signifikan terhadap kinerja pegawai (Y) pada Puskesmas Rantau Ikil Kabupaten Bungo. Hal ini terlihat dari nilai thitung $(8,533)>t_{\text {tabel }}$ (1,98861), sehingga $\mathrm{H}_{0}$ ditolak dan $\mathrm{H}_{\mathrm{a}}$ diterima. 
2. Secara simultan dilihat bahwa nilai $F_{\text {hitung adalah }(75,156)}$ lebih besar dari $F_{\text {tabel }}(3,280)$. sehingga $\mathrm{H}_{0}$ ditolak dan $\mathrm{H}_{\mathrm{a}}$ diterima. Maka dapat disimpulkan bahwa variabel motivasi kerja $\left(\mathrm{X}_{1}\right)$ dan disiplin kerja $\left(\mathrm{X}_{1}\right)$ secara simultan berpengaruh positif dan signifikan terhadap kinerja (Y) pegawai Puskesmas Rantau Ikil Kabupaten Bungo.

\section{Saran}

Diketahui bahwa motivasi kerja memiliki nilai lebih rendah dibanding disiplin, maka disarankan agar pegawai dapat meningkatkan tanggung jawab dalam melakukan kerja, meningkatkan Prestasi yang dicapainya, lebih mengembangkan diri dan mandiri dalam bertindak, sehingga kinerja dapat ditingkatkan.

\section{DAFTAR PUSTAKA}

Darsono dan Siswandoko, Manajemen Sumber Daya Manusia Nusantara Consulting. 2011.

Hamzah B. Uno. 2009. Teori dan Motivasi dan Pengukurannya (Analisis dibidang Pendidikan). PT. Bumi Aksara. Jakarta.

Hasibuan, S.P. Malayu. 2012. Manajemen Sumber Daya Manusia, Edisi Revisi. Bumi Aksara, Jakarta.

Mangkunegara, A.A. Anwar Prabu, "Mamajemen Sumber Daya Manusia Perusahaan”, PT Remaja Rosdakarya, Bandung, 2015.

Mangkunegara, Anwar Prabu (2011). Manajemen Sumber Daya. Perusahaan. Remaja Rosdakarya, Bandung.

Sugiyono, 2015. Metode Penelitian Kuantitatif Dan Kualitatif. Bandung: Cv. Alfabeta

Yohanes Delvin Ardianto (2017 Analisis Pengaruh Motivasi Kerja Dan Disiplin Kerja Terhadap Kinerja Karyawan Devisi Pabrikasi Direktorat Produksi PT. Industri Kereta Api (PT.INKA) Maldiun, Fakultas Ekonomi Universitas Sanata Dharma Yogyakarta 